\title{
Predicting the Performance Uncertainty of a 1-MW Pilot-scale Carbon Capture System after Hierarchical Laboratory-scale Calibration and Validation
}

Zhijie $\mathrm{Xu}^{1 *}$, Canhai Lai ${ }^{1}$, Peter William Marcy ${ }^{2}$, Jean-François Dietiker ${ }^{3}$, Tingwen $\mathrm{Li}^{3}$, Avik Sarkar $^{4}$, Xin Sun $^{1}$

* Zhijie.Xu@pnnl.gov

1 Pacific Northwest National Laboratory, Richland, WA 99352

2 Los Alamos National Laboratory, Los Alamos, NM 87545

3 National Energy Technology Laboratory, Morgantown, WV 26507

4 Current affiliation: Pfizer Inc., Groton, CT 06340

\begin{abstract}
A challenging problem in designing pilot-scale carbon capture systems is to predict, with uncertainty, the adsorber performance and capture efficiency under various operating conditions where no direct experimental data exist. Motivated by this challenge, we previously proposed a hierarchical framework where relevant parameters of physical models were sequentially calibrated from different laboratory-scale carbon capture unit (C2U) experiments. Specifically, three models of increasing complexity were identified based on the fundamental physical and chemical processes of the sorbent-based carbon capture technology. Results from the corresponding laboratory experiments were used to statistically calibrate the physical model parameters while quantifying some of their inherent uncertainty. In this study, the parameter distributions obtained from laboratory-scale $\mathrm{C} 2 \mathrm{U}$ calibration runs are used to facilitate prediction at a larger scale with no corresponding experimental results available. Initially, we describe the multiphase reactive flow model for a sorbent-based 1megawatt carbon capture system then analyze results from an ensemble of simulations with the upscaled model. The simulation results are used to quantify uncertainty regarding the
\end{abstract}


design's predicted efficiency in carbon capture. In particular, we determine the minimum gas flow rate necessary to achieve 90 percent capture efficiency with 95 percent confidence.

\section{Keywords}

Computational fluid dynamics, bubbling bed, carbon capture, model validation, multiphase reactive flow, uncertainty quantification 


\section{Introduction}

Flue gas produced during coal combustion at coal-fired power plants contains a large amount of carbon dioxide $\left(\mathrm{CO}_{2}\right)$ and, when directly released to the atmosphere, is a major contributor to global climate change. Carbon capture and sequestration can be an effective way to reduce the amount of $\mathrm{CO}_{2}$ emissions and form part of a strategy to stabilize global climate change. As stated in [1], "achieving substantial reductions in temperatures relative to the coal-based systems will depend on rapid and massive deployment of some mix of conservation, wind, solar, and nuclear, and possibly carbon capture and storage." However, it is well recognized that current carbon capture and storage technologies must improve and mature before contributing to any significant portion of the mitigation portfolio. In practical terms, technological improvements during scale up are vital for commercial viability within the power generation sector [2,3]. To accelerate development and deployment of postcombustion carbon capture technology, the Carbon Capture Simulation Initiative (CCSI), a partnership between U.S. Department of Energy (DOE) national laboratories, industry, and universities, was created to improve the state-of-the-art computational modeling and simulation tools employed for efficient carbon capture [4].

Much research has been devoted to developing carbon capture technology that minimizes the energy penalty to coal-fired power plants [5]. As an alternative to amine-based aqueous solvents that require high energy costs for regeneration, scientists at the National Energy Technology Laboratory (NETL) have developed amine-based solid sorbents [6] to capture $\mathrm{CO}_{2}$ from flue gas with a reduced energy penalty, minimal water use, negligible corrosion, and fewer operational issues [7]. Most of the work involving solid sorbents contributes to the development of the sorbent itself, while only limited studies focus on the design of an entire 
reactor system using computational tools. Recently, a computational fluid dynamics (CFD) model was developed in FLUENT to explore the innovative reactor design using a rotating fixed bed [8]. In the past, several modeling studies have evaluated small-scale solid sorbent adsorber performance [9] using a single CFD model, as well as CFD models developed in FLUENT and BARRACUDA [10], where the strengths and weaknesses of different CFD models are explored for the same small-scale reactor design. However, few studies have addressed the challenging problem to predict, with uncertainty, pilot-scale adsorber performance with no existing direct experimental data, which is the focus of this paper.

Solid sorbent-based capture systems are inherently complex and involve complicated multiphase, multiphysics, and multiscale phenomena. In CCSI, high-fidelity CFD models for multiphase reactive flow have been developed to simulate the complex physical and chemical processes of sorbent-based carbon capture and gain more insights on flow field and reaction behaviors in reactors using the open-source Multiphase Flow with Interphase eXchanges (MFIX) (https://mfix.netl.doe.gov) code. Although MFIX has been independently verified for various simple and small-scale multiphase reactive flow problems [11-13], rigorous model validation with quantified confidence on quantities of interest must be performed when such simulations are executed at the pilot scale and the results subsequently are used to inform system-level designs and decision-making. Because it is not currently feasible to conduct a direct model validation for the 1-megawatt (MW) pilot-scale carbon capture system due to the lack of experimental data at that scale, the MFIX-based CFD predictions must be progressively validated and calibrated so the predictive confidence at scale can be quantitatively characterized through statistical-based uncertainty propagation. 
To accomplish this, CCSI has developed a hierarchical calibration and validation framework for solid sorbent-based capture (Fig. 1) [14, 15]. Starting from the very bottom layer in Figure 1, the complex physics and chemical processes of carbon capture are first decoupled into several unit problems with increasing levels of complexity. Each unit problem represents a unique model component that targets individual physics, including hydrodynamics, heat transfer, and chemical reactions.

A laboratory-scale carbon capture unit $(\mathrm{C} 2 \mathrm{U})$, built at NETL (shown on the experiment side in Fig. 1), provides the experimental data for hierarchical model validation, and a batch of experiments has been carried out with various control parameters to reproduce the unit problems. More details about the $\mathrm{C} 2 \mathrm{U}$ experiment design and results can be found in our previous study on the hierarchical calibration and validation of carbon capture models for C2Us [16]. The entire validation process includes step-by-step model validation with increasing model complexity by introducing new physics and governing equations with associated model parameters into the previously validated and calibrated models. Beginning with cold non-reacting flow to hot non-reacting flow and subsequently to hot reacting flow with chemical reactions, a series of parallel $\mathrm{C} 2 \mathrm{U}$ experiments have been conducted to provide data for model parameter calibration at each step of the $\mathrm{C} 2 \mathrm{U}$ model validation hierarchy. A Bayesian calibration procedure, where the posterior distributions of model parameters obtained at each unit-problem level are used as prior distributions for the same parameter set in the next level of the unit problem, is employed.

Following this validation hierarchy, model parameters critical to carbon capture prediction have been identified and calibrated [1]. The posterior distributions of these parameters based on Bayesian calibration now will enable at-scale prediction for the pilot- 
scale design with a predictive confidence interval. This paper focuses on applying the validated and calibrated multiphase reactive models at the laboratory scale to quantify the prediction confidence for the conceptual 1-MW pilot-scale carbon capture design (the shaded elliptic box in Fig. 1).

The paper is organized as follows: Section 2 describes the conceptual design of the 1MW pilot-scale adsorber with geometry, dimension, and typical operating conditions. The corresponding CFD models for the 1-MW pilot-scale adsorber are presented in Section 3. Section 4 introduces the nominal settings for the simulations and statistical data analysis that result in a confidence interval for the at-scale predictions. The paper concludes with Section 5.

\section{1-MW Pilot-scale Adsorber Conceptual Design}

\subsection{Adsorber Geometry and Operation Conditions}

Typical pilot-scale $\mathrm{CO}_{2}$ capture systems consist of two main components: 1) the bubbling bed adsorber and 2) moving bed regenerator. These components operate continuously to process the constant stream of flue gas generated by a coal-fired power plant. In the adsorber, $\mathrm{CO}_{2}$ is extracted from the exhaust flue gas by means of chemically active sorbent particles. The $\mathrm{CO}_{2}$-saturated sorbent particles are taken to the regenerator, wherein the captured $\mathrm{CO}_{2}$ is released from the saturated particles. Subsequently, the refreshed sorbent particles are returned to the adsorber.

Figure 2 (left) shows the schematic geometry and dimensions of the two-stage countercurrent flow adsorber. Fresh sorbent particles enter the adsorber column from the top and exit from the outlet on the right side, while hot flue gas enters from the bottom of the adsorber and lean gas exits from the top. The entire adsorber column is divided into two 
stages, each separated by perforated trays that allow flue gas to move upward. The whole adsorber column is distributed with cooling rods to cool down the flue gas, affording better $\mathrm{CO}_{2}$ adsorption by the solid particles. Eventually, $\mathrm{CO}_{2}$-loaded sorbent particles leave the adsorber system and enter the regenerator column. As is typical for trayed-column systems, the top stage is connected to the lower stage to facilitate better $\mathrm{CO}_{2}$ adsorption. Two distributor plates are located at the bottom and top of the adsorber, which allow the gas phase to pass through. In this study, the MFIX model (Section 3.2) simulates only the lower stage of the adsorber column.

The lower stage (tray) has a height of $6.88 \mathrm{~m}$ with the lower $5.88 \mathrm{~m}$ occupied by vertical heat exchanger tubes to improve $\mathrm{CO}_{2}$ adsorption by cooling the flue gas and effectively removing the heat generated by the exothermic adsorption reaction. These tubes are extended well above the top surface $(\sim 1 \mathrm{~m})$ of the bed into the freeboard area. The cooling tubes have a diameter of $0.01 \mathrm{~m}$, and their spacing is $0.111 \mathrm{~m}$. Refer to Figure 2 (right) for the designed tube arrangement. The overall volume fraction of the cooling tubes is about 0.64 percent. No cooling tubes are present in the downcomer section.

\subsection{Chemistry of Carbon Capture in the Adsorber}

A first-order chemistry model for chemical kinetics is used to model the adsorption and desorption of $\mathrm{CO}_{2}$ and water vapor onto amine-based sorbent particles of type NETL-32D (developed at NETL). Additional details regarding this particular type of solid sorbent can be found in our previous study [16]. The chemical reactions considered in the current kinetics model include $[17,18]$ :

1) Reaction of $\mathrm{CO}_{2}$ with the impregnated amine to form carbamate, i.e., dry adsorption

2) Reaction of $\mathrm{CO}_{2}$, physisorbed $\mathrm{H}_{2} \mathrm{O}$, and amine to form bicarbonate, i.e., wet adsorption 
3) Physical adsorption of $\mathrm{H}_{2} \mathrm{O}$ to the sorbent, i.e., water physisorption.

Equations for the three respective reactions are written as:

$$
\begin{aligned}
& 2 \mathrm{R}_{2} \mathrm{NH}+\mathrm{CO}_{2}(g) \leftrightarrow \mathrm{R}_{2} \mathrm{NCO}_{2}^{-}+\mathrm{R}_{2} \mathrm{NH}_{2}^{+}, \\
& \mathrm{R}_{2} \mathrm{NH}+\mathrm{H}_{2} \mathrm{O}(\text { phys })+\mathrm{CO}_{2}(g) \leftrightarrow \mathrm{HCO}_{3}^{-}+\mathrm{R}_{2} \mathrm{NH}_{2}^{+}, \\
& \mathrm{H}_{2} \mathrm{O}(\mathrm{g}) \leftrightarrow \mathrm{H}_{2} \mathrm{O}(\text { phys }) .
\end{aligned}
$$

The following reaction rates for all three chemical equations can be derived by assuming most species react ideally:

$$
\begin{aligned}
& \frac{\partial \mathrm{x}}{\partial \mathrm{t}}=\mathrm{k}_{\mathrm{c}}\left(\mathrm{s}^{2} \mathrm{p}_{\mathrm{c}}-\frac{\mathrm{xw}}{\mathrm{K}_{\mathrm{c}}}\right) \\
& \frac{\partial \mathrm{b}}{\partial \mathrm{t}}=\mathrm{k}_{\mathrm{b}}\left(\operatorname{sap}_{\mathrm{c}}-\frac{\mathrm{bw}}{\mathrm{K}_{\mathrm{b}}}\right) \\
& \frac{\partial \mathrm{a}}{\partial \mathrm{t}}=\mathrm{k}_{\mathrm{h}}\left(\mathrm{p}_{\mathrm{h}}-\frac{\mathrm{a}}{\mathrm{K}_{\mathrm{h}}}\right)
\end{aligned}
$$

where $\mathrm{x}, \mathrm{b}$, and a are carbamate anion site fraction, bicarbonate concentration, and adsorbed water concentration, respectively. The respective equilibrium and rate constants are defined as:

$$
\begin{aligned}
& \mathrm{K}_{\mathrm{q}}=\mathrm{e}^{\frac{\Delta \mathrm{S}_{\mathrm{q}}}{\mathrm{R}}} \mathrm{e}^{\frac{-\Delta \mathrm{H}_{\mathrm{q}}}{\mathrm{RT}}} / \mathrm{P}, \\
& \mathrm{k}_{\mathrm{q}}=\zeta_{\mathrm{q}} \mathrm{Te}^{\frac{-\Delta \mathrm{H}_{\mathrm{q}}^{\ddagger}}{\mathrm{RT}}}
\end{aligned}
$$

where

$$
\begin{aligned}
& 1=\mathrm{s}+\mathrm{w}+\mathrm{x}, \\
& \mathrm{w}=\mathrm{x}+\mathrm{b} / \mathrm{n}_{\mathrm{v}}
\end{aligned}
$$

with symbols defined in Table 1 . The subscript $q=c, b$, or $h$ corresponds to the three reactions, respectively. 
Table 1. Nomenclature in chemical reaction equations

\begin{tabular}{|ll|}
\hline $\mathrm{w}$ & protonated amine site fraction \\
$\mathrm{s}$ & free amine site fraction \\
$\mathrm{p}_{\mathrm{c}}$ & $\mathrm{CO}_{2}$ partial pressure \\
$\mathrm{p}_{\mathrm{h}}$ & $\mathrm{H}_{2} \mathrm{O}$ partial pressure \\
$\mathrm{P}$ & total pressure (97189.3 Pa; average barometer for TGA test) \\
$\mathrm{n}_{\mathrm{v}}$ & number of amine sites per unit volume (e.g., $\left.2351.0 \mathrm{~mol} / \mathrm{m}^{3}\right)$ \\
\hline
\end{tabular}

The hierarchical calibration and validation process has been used to calibrate the sorbent chemistry model as reported by Lai et al. [16]. Experimental data obtained from thermogravimetric analysis (TGA) under different operating conditions further assist in calibrating the chemical reaction rates and equilibrium constants $\Delta \mathrm{H}_{\mathrm{q}}, \Delta \mathrm{S}_{\mathrm{q}}, \Delta \mathrm{H}_{\mathrm{q}}^{\ddagger}$, and $\zeta_{\mathrm{q}}$. Table 2 summarizes the posterior means of the reaction rate parameters obtained from the final C2U study and are used for the 1-MW pilot-scale nominal simulations. The entire posterior distribution for all parameters can be found in [16].

Table 2. Posterior mean values of chemistry parameters used for nominal cases

\begin{tabular}{|l|l|l|l|l|}
\hline & $\Delta \mathrm{H}(\mathrm{J} / \mathrm{mol})$ & $\Delta \mathrm{S}(\mathrm{J} / \mathrm{mol} \cdot \mathrm{K})$ & $\Delta \mathrm{H}^{\ddagger}(\mathrm{J} / \mathrm{mol})$ & $\log _{10} \zeta$ \\
\hline Dry Adsorption & -90599 & -221.60 & 54112 & 1.5142 \\
\hline Wet Adsorption & -83043 & -276.49 & 79206 & 2.8956 \\
\hline Water Physisorption & -95457 & -211.36 & 60770 & 3.1461 \\
\hline
\end{tabular}

\section{Computational Models for 1-MW Pilot-scale Adsorber}

\subsection{Fundamentals of Multiphase Reactive Flow and MFIX}


The open-source multiphase flow solver MFIX is used to conduct all simulations, and the two-fluid model (TFM) is selected from the available modeling suite (https://mfix.netl.doe.gov/). MFIX-TFM is an Eulerian-Eulerian model where the gas and solid phases are considered to be interpenetrating continuum. Momentum transfer between phases is achieved through empirical drag laws. The constitutive relations are formulated so they can accommodate the full range of the flow regime, from dilute to dense granular flows. In the plastic regime, Schaeffer's frictional theory is used [19]. Above close packing, the particle-particle interactions are modeled through the kinetic theory of granular flow [20]. The full set of governing equations solved in MFIX is summarized in [21]. Additional details about multiphase flow theory and the numerical techniques employed in MFIX are provided in $[21,22]$. The gas phase is composed of four chemical species $-\mathrm{N}_{2}, \mathrm{O}_{2}, \mathrm{CO}_{2}$, and water vapor - and the solids phase (sorbent) comprises six chemical species (see Section 2.2). A total of 20 transport equations must be solved at each time step: two continuity, six momentum, two energy, and 10 species equations.

\subsection{Geometric Coarse-graining in MFIX with Filtered Models}

Device-scale CFD simulations are particularly challenging, especially where grid sizes smaller than 10 particle diameters are needed to explicitly resolve the fine-scale particle clusters [23] because more than three billion cells are needed for such three-dimensional (3D) models. An alternate approach involves using filtered models wherein coarser cells may be employed, and the effects of unresolved fine-scale structures are incorporated via filtered sub-grid corrections [24-30]. 
For fluidized beds, the correction to gas-particle drag is especially significant [31]. The filtered gas-particle drag force generally is expressed as a correction to the microscopic drag model (such as $[32,33]$ ), and the correction itself typically is a function of the solid fraction [30, 34] and gas-particle slip velocity [29]. Other hydrodynamic filtered corrections also are applied to the solids pressure and viscosity.

Our system includes two regions: 1) an upper freeboard region and 2) lower region occupied by an array of cooling tubes (Fig. 2). In the lower region, the cooling tube dimensions ( $10 \mathrm{~mm}$ diameter) are too small to be resolved explicitly by the CFD mesh $(\sim 18.5 \mathrm{~mm})$. Although these tubes occupy a small overall volume $(0.64 \%)$, they have direct impact on the flow. In addition to participating in heat transfer, the cylinders exert direct drag on the suspension and modify the filtered gas-solid drag correction [30]. Therefore, we use the filtered hydrodynamic sub-grid corrections given by [30] for the lower region, where the cylinders are replaced by a stationary, porous solids phase occupying an equivalent volume. The cylinder-suspension heat transfer in this region is modeled with the filtered relationships given by [35], which accounts for the tubes' cooling effects (now modeled as a porous solids phase). For the upper region without cylinders, we use the standard filtered model by [34]. Using these filters enables quantitatively accurate predictions, even with grid sizes $\sim 100$ times the particle diameter $[26,27,36]$.

\subsection{MFIX Model Setup, Boundary, and Initial Conditions}

This section includes a detailed description of the MFIX model for the lower-stage absorber column. A two-dimensional (2D) MFIX model is built for the $1.33 \mathrm{~m} \times 6.88 \mathrm{~m}$ adsorber column. The entire domain is discretized into $72 \times 372$ grids. As shown in Figure 
3(b), the solids inlet is modeled as a mass flow inlet at the top-left corner of the adsorber column. The gas that occupies the interstices between the entering solid particles is assigned an inlet velocity comparable to that of the solids. The corresponding solids outlet on the right side is specified as a constant pressure/temperature mass outflow outlet in MFIX.

The flue gas inlet is located at the bottom of the adsorber column and described with a mass inflow boundary condition. The inlet mass flow rate for flue gas is a controllable parameter, and its effect on the adsorber's overall capture efficiency will be investigated in detail. Gas exits the adsorber from the top of the column, where a constant pressure outlet is used. To prevent sorbents from escaping either from the bottom inlet or top outlet, a semipermeable membrane is applied to allow only the gas phase to pass through. Figure 3(b) summarizes the solid and gas inlets and outlets from the conceptual design. Sorbent particles enter through the downcomer to the fluidized bed region, where most chemical reactions and heat transfer occur, and exit from the solid outlet at a height of 4.773 (shown as B.C. 4 in Fig. 3(d)). The flue gas flows into the fluidized bed from the bottom distributor plate and exits from the gas outlet at the top of the adsorber. The solid sorbent particles have a density of $484 \mathrm{~kg} / \mathrm{m}^{3}$ with an average size of $118 \mu \mathrm{m}$. The minimum fluidized velocity can be computed to be $\sim 0.226 \pm 0.024 \mathrm{~cm} / \mathrm{s}$.

Figures 3(c) and 3(d) illustrate the setup of the CFD model's initial and boundary conditions using MFIX. Two internal surfaces at the top and bottom are used to mimic the respective distributor plates. The corresponding initial and boundary conditions are listed in Tables 3 and 4, respectively, for nominal simulations. A mixture of gases initially fills the adsorber column. Table 3 lists all field variables (pressure, temperature, and composition) 
used for the gas phase for all three initial conditions. The only difference is the void fraction due to the presence of the heat exchanger tubes.

Operational parameters needed for boundary conditions include the gas phase parameters (flow rate, pressure, temperature, and composition) for the gas inlet (B.C. 1 in Fig. 3(d) with a solid volume fraction of 0 ) and solid phase parameters (flow rate, temperature, and composition) for the solid inlet (B.C. 2 in Fig. 3(d) with a solid volume fraction of 0.5). "From Sim" in Table 4 denotes variables at the solid and gas outlet that can be computed from simulations.

Table 3. Initial conditions for the CFD model of the nominal case

\begin{tabular}{|c|c|c|c|c|c|}
\hline & $\begin{array}{c}\text { Initial } \\
\text { Condition } \\
1\end{array}$ & $\begin{array}{c}\text { Initial } \\
\text { Condition } \\
2\end{array}$ & $\begin{array}{c}\text { Initial } \\
\text { Condition } \\
3\end{array}$ & $\begin{array}{c}\text { Internal } \\
\text { Surface 1 } 1\end{array}$ & $\begin{array}{c}\text { Internal } \\
\text { Surface 2 }\end{array}$ \\
\hline Voidage (EP_g) & 1.0 & 0.9936 & 0.9936 & \\
\hline \multicolumn{2}{|c|}{$\begin{array}{c}\text { Gas pressure } \\
\left(\mathrm{P}_{\mathrm{g}}: \mathrm{P}_{\mathrm{a}}\right)\end{array}$} & $1.01 \times 10^{5}$ & $1.01 \times 10^{5}$ & $1.01 \times 10^{5}$ & \\
\cline { 1 - 4 } $\begin{array}{c}\text { Gas temperature } \\
\left(\mathrm{T}_{\mathrm{g}}: \mathrm{K}\right)\end{array}$ & 313.15 & 313.15 & 313.15 & $\begin{array}{c}\text { Semipermeable } \\
\text { (allows gas flow } \\
\text { through the surface } \\
\text { but not the solids) }\end{array}$ \\
\cline { 1 - 4 } $\begin{array}{c}\text { Gas phase } \\
\text { mass } \\
\text { fraction }\end{array}$ & $\mathrm{N}_{2}$ & 0.73 & 0.73 & 0.73 & \\
\cline { 2 - 5 } & $\mathrm{CO}_{2}$ & 0.05 & 0.05 & 0.05 & \\
\cline { 2 - 5 } & $\mathrm{H}_{2} \mathrm{O}(\mathrm{g})$ & 0.02 & 0.02 & 0.02 & \\
\cline { 2 - 5 } & $\mathrm{O}_{2}$ & 0.20 & 0.20 & 0.20 & \\
\hline
\end{tabular}


Table 4. Boundary conditions for the CFD model of the nominal case

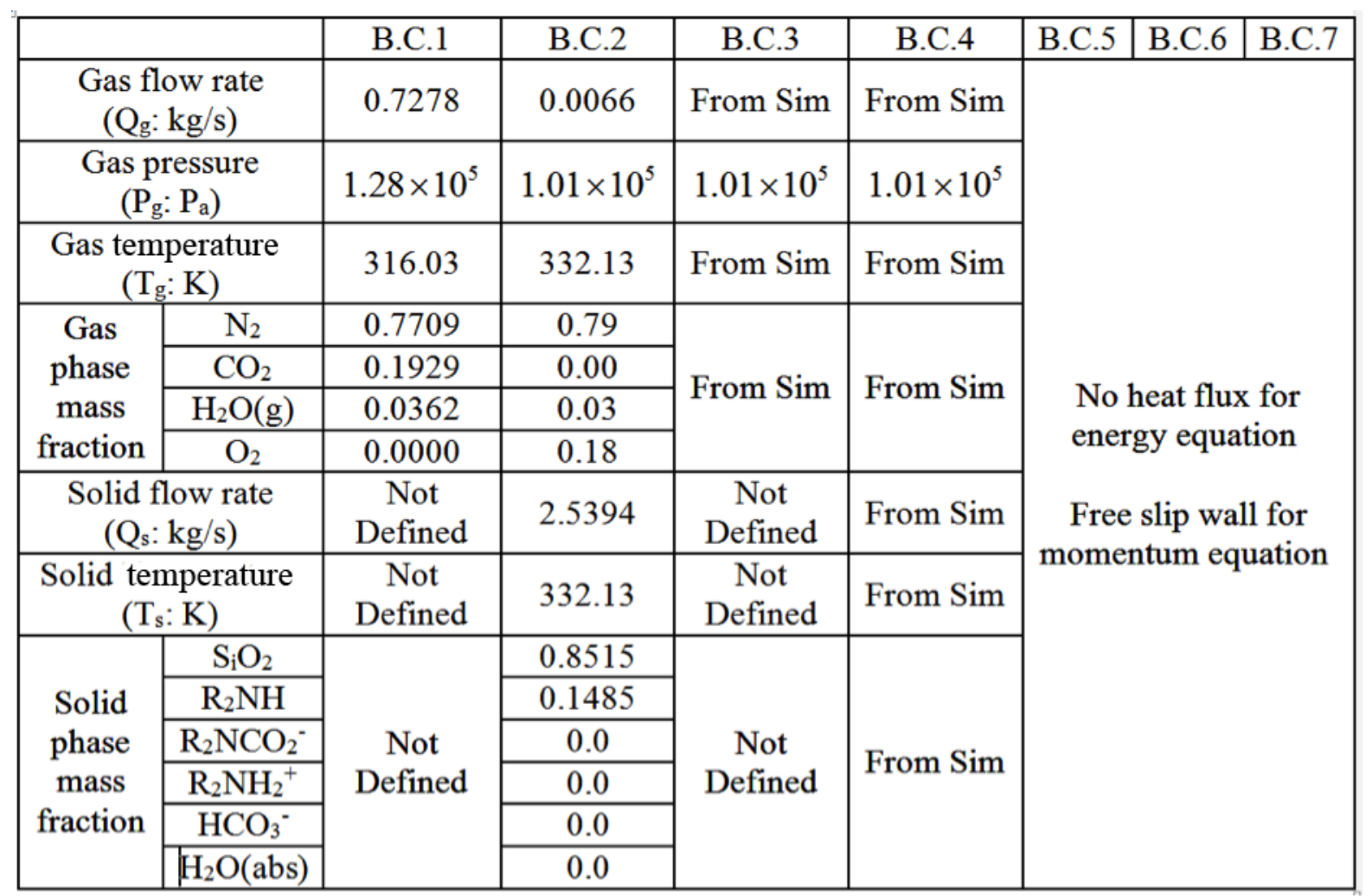

\section{Numerical Implementation and Results for 1-MW Simulations}

In our previous study [16], we developed CFD models with increasing complexity corresponding to the three unit problems (cold non-reacting flow, hot non-reacting flow, and hot-reacting flow) and validated them with relevant laboratory-scale C2U experiments (Fig. 1). For each unit problem, a Bayesian statistical calibration routine was used to assess the discrepancy between experimental and simulated data and to quantify various parametric uncertainties. The final calibration for the hot-reacting flow case produced posterior distributions for 15 uncertain and unobservable physical parameters: 12 for chemical reactions (four each for dry reaction, wet reaction, and physisorption) and three for physical properties of the sorbent particles (refer to Fig. 23 in [16]). Markov chain Monte Carlo 
(MCMC) was used to obtain a sample from these distributions. The focus of the present analysis is to propagate a subsample through the 1-MW model and analyze the resulting uncertainty for predicted bed height and fraction of $\mathrm{CO}_{2}$ adsorbed.

In this study, 300 vectors of the 15 uncertain parameters are drawn from their joint posterior distribution obtained from the final analysis in [16] and used as the input configurations of the 1-MW simulations at five different gas flow rates: $0.36,0.48,0.60,0.72$, and $0.84 \mathrm{~kg} / \mathrm{s}$. For each flow rate setting, one additional run is conducted at the posterior mean value of the parameters (the nominal simulation run), resulting in a total of $301 \times 5=$ 1505 runs for the uncertainty analysis of $\mathrm{CO}_{2}$ capture fraction and bed height. The results at the posterior mean can be viewed as the nominal case, and the specific values for these inputs can be found in Table 2. In the remainder of this section, we first will provide details regarding the 1-MW model runs. Then, we will describe the simulation at the nominal input values. Finally, we will offer a statistical analysis of the uncertainty across all simulations that run to completion.

\subsection{Numerical Details and Nominal Simulation Results}

To achieve steady-state operation, all simulations are run to 600 seconds. A typical parallel simulation with 20 processors will take one to five days to finish the 600 -second simulation. The production runs were conducted on PNNL Institutional Computing (PIC) high-performance computer clusters. Additional simulations have been conducted on the NETL Simulation-Based Engineering User Center (SBEUC) supercomputer. The computational cost is heavily influenced by the chemical reaction parameters. When the combination of parameters makes the reactive system stiff, the computational time step must 
be continuously reduced, which results in a significant increase in computational cost. In comparison, without the chemical reaction, a typical simulation usually takes less than 24 hours to finish the same 600 -second simulation. Similar to the C2U simulations reported in previous work [16], certain combinations of chemistry parameters result in failed MFIX simulations. Because no output is produced in these failed runs, they cannot be considered in the subsequent uncertainty analysis for 1-MW performance predictions.

The most important quantity of interest for 1-MW pilot-scale prediction is the overall capture efficiency of the designed adsorber column. This is calculated with the formula:

$$
E=\left(Q_{\mathrm{CO}_{2}}^{\text {in }}-Q_{\mathrm{CO}_{2}}^{\text {out }}\right) / Q_{\mathrm{CO}_{2}}^{\text {in }}
$$

where $E$ is the overall capture fraction for $\mathrm{CO}_{2}$. The inlet $\mathrm{CO}_{2}$ flow rates $\left(Q_{\mathrm{CO}_{2}}^{i n}\right)$ are given from the boundary condition (B.C. 1 in Fig. 3(d)), while the flow rate of $\mathrm{CO}_{2}\left(Q_{\mathrm{CO}_{2}}^{\text {out }}\right)$ at the outlet (B.C. 3 in Fig. 3(d)) is directly calculated from the MFIX simulation. The bed height is estimated by the location where void fraction shows an abrupt jump. $\mathrm{Most} \mathrm{CO}_{2}$ adsorption is completed within a $1 \mathrm{~m}$ range of the bottom of the adsorber.

Nominal simulations use the posterior means of all 15 important parameters from the Bayesian calibration of the $\mathrm{C} 2 \mathrm{U}$ model (chemistry together with amine molar fraction and particle size). Table 2 lists the chemistry parameter values. Amine molar fraction is set to its posterior mean of 0.1438 and particle size to $117.90 \mu \mathrm{m}$. The nominal simulations represent the adsorber behavior under typical or expected operating conditions. Tables 3 and 4 feature all of the initial and boundary conditions used for these nominal cases.

Figure 4 presents the spatial distribution of voidage, gas phase temperature, and $\mathrm{CO}_{2}$ mass fraction from nominal simulations at $t=600$ seconds. In particular, the void fraction distribution (Fig. 4(a)), or, equivalently, the volume fraction of sorbent particles, can be used 
to compute the fluidized bed height. Figure 4(b) plots the gas phase temperature distribution, where the bottom of the fluidized bed has a relatively higher temperature because of significant heat generation from $\mathrm{CO}_{2}$ adsorption. Figure 4(c) presents the distribution of $\mathrm{CO}_{2}$ mass fraction, where most $\mathrm{CO}_{2}$ adsorption occurs at the bottom of the adsorber column at the given gas flow rate, $0.60 \mathrm{~kg} / \mathrm{s}$. Figure 5 features the quantitative descriptions of void and mass fraction of $\mathrm{CO}_{2}$ and $\mathrm{H}_{2} \mathrm{O}$ along the height of the adsorber column, where a crosssectional average of these quantities is implemented at different heights. The abrupt increase in void fraction indicates the fluidized bed's range. While chemical adsorption of $\mathrm{CO}_{2}$ mostly occurs at the bottom of adsorber with little $\mathrm{CO}_{2}$ in the freeboard region beyond the height of the fluidized bed, the fraction of $\mathrm{H}_{2} \mathrm{O}$ does not change significantly along the column height.

\subsection{Uncertainty Analysis for the 1-MW Pilot-scale Adsorber}

DOE has set the target for carbon capture efficiency at 90 percent. In this section, our simulation framework will be used to predict carbon capture efficiency with quantitative confidence to answer the following question: For this conceptual adsorber design, at what inlet gas flow rate can we be 95 percent certain to obtain 90 percent capture?

To examine the impact of gas flow rate on $\mathrm{CO}_{2}$ capture efficiency, MFIX simulations with different flow rates, namely $0.36,0.48,0.60,0.72$, and $0.84 \mathrm{~kg} / \mathrm{s}$, are conducted. Figure 6 shows snapshots of the fluidized bed for three flow rates: $0.36,0.6$, and $0.84 \mathrm{~kg} / \mathrm{s}$. As the gas flow rate increases, the fluidized bed height increases. As a result, void fraction in the fluidized bed increases (or, equivalently, solid fraction decreases). Figure 7 shows the corresponding $\mathrm{CO}_{2}$ mass fraction in the entire adsorber for the same three flow rates. At a relatively low gas flow rate, adsorption is significant at the very bottom of the adsorber, 
which contrasts with widely spread adsorption along the adsorber at a relatively high gas flow rate. Figure 8 shows the transient variation of $\mathrm{CO}_{2}$ absorption fraction with time. The gas flow rate dependence of the steady state absorption fraction can be clearly obseved.

The overall adsorber column performance can be represented by the $\mathrm{CO}_{2}$ capture fraction, which is computed via Eq. (11). From the results presented in Figure 9 for the nominal cases, it is evident that the total $\mathrm{CO}_{2}$ capture rate increases with increasing gas flow rate, thus increasing the $\mathrm{CO}_{2}$ amount. However, as the amount of amine remains fixed in quantity, the $\mathrm{CO}_{2}$ capture fraction begins to decrease.

Figure 10 plots the probabability density of $\mathrm{CO}_{2}$ capture fraction and bed height from a batch of simulations with a flow rate of $0.72 \mathrm{~kg} / \mathrm{s}$. It is important to note that the 1-MW prediction at the nominal input (given by the green " $x$ " and line segment) is far too optimistic. The remaining uncertainty distribution must be taken into consideration (capture fractions can be as low as 0.81 due to specific input value uncertainty).

Figure 11 features side-by-side boxplots that show the resulting uncertainty distributions for capture fraction at each flow rate together with the value obtained from running the simulator at the nominal input values. Figure 11 also displays statistical estimates of the predicted mean, or best guess, of $\mathrm{CO}_{2}$ capture (blue curve) and predicted fifth percentile (95\% lower bound, red curve). The predicted mean is estimated using a generalized linear model with a logit link function. The logit transformation is necessary because the response variable takes on values within the interval $[0,1]$. Weighted quantile regression on the logit scale is used to estimate the fifth percentile of the uncertainty distributions across flow rates. Lower weights are given to the two lowest flow rates. The estimated percentiles then are transformed back to the original scale. 
Although the best guess of capture performance, i.e., the predicted mean, is greater than 0.90 for all flow rates, variability across the ensemble of 1-MW runs needs to be considered. To this end, the quantile regression analysis allows us to conclude that we may be 95 percent confident that a flow rate of roughly $0.72 \mathrm{~kg} / \mathrm{s}$ will result in a capture fraction of, at least, 90 percent.

\section{Conclusion}

In this paper, we have quantified the uncertainty of $\mathrm{CFD}$-predicted $\mathrm{CO}_{2}$ capture efficiency and bed height for a 1-MW pilot-scale bubbling fluidized bed reactor, starting from the calibration results given in our previous work [16].

A fully coupled multiphase reactive flow CFD model with chemical reaction, energy, and species transport has been developed to solve the spatial and temporal distributions of flow,

temperature, and species composition, as well as to predict the device's overall performance in $\mathrm{CO}_{2}$ capture. The developed $\mathrm{CFD}$ model integrates the $2 \mathrm{D}$ cylinder drag and heat transfer filtered models required for simulations at pilot scale with a manageable computational burden. Nominal simulations show that overall $\mathrm{CO}_{2}$ capture efficiency decreases with increasing gas flow rate. A statistical analysis has been performed to obtain a prediction interval that quantifies uncertainty within the prediction of capture efficiency. For this particular pilot-scale design, our prediction has shown — with 95 percent confidence—-that a gas flow rate of $0.72 \mathrm{~kg} / \mathrm{s}$ will deliver a $\mathrm{CO}_{2}$ capture fraction of, at least, 90 percent.

With this work, we also have demonstrated that the hierarchical validation and calibration framework for the performance of a 1-MW pilot-scale carbon capture system, as proposed in 
[16], can be readily used to quantify uncertainty when predicting device performance at a scale where no experimental data are available for direct model validation.

\section{Acknowledgments}

Pacific Northwest National Laboratory is operated by Battelle for the U.S. Department of Energy under Contract DE-AC05-76RL01830. This work was funded by the DOE Office of

Fossil Energy's Carbon Capture Simulation Initiative through the National Energy Technology Laboratory. 


\section{Disclaimer}

This manuscript was prepared as an account of work sponsored by an agency of the United States Government. Neither the United States Government nor any agency thereof, nor any of their employees, makes any warranty, express or implied, or assumes any legal liability or responsibility for the accuracy, completeness, or usefulness of any information, apparatus, product, or process disclosed, or represents that its use would not infringe privately owned rights. Reference herein to any specific commercial product, process, or service by trade name, trademark, manufacturer, or otherwise does not necessarily constitute or imply its endorsement, recommendation, or favoring by the United States Government or any agency thereof. The views and opinions of authors expressed herein do not necessarily state or reflect those of the United States Government or any agency thereof. 


\section{References}

[1] N. P. Myhrvold and K. Caldeira, Environmental Research Letters 7, 014019 (2012).

[2] L. M. Abadie, I. Galarraga, and D. Rubbelke, Environmental Modelling \& Software 54, $182(2014)$.

[3] R. S. Haszeldine, Science 325, 1647 (2009).

[4] D. C. Miller, M. Syamlal, D. S. Mebane, C. Storlie, D. Bhattacharyya, N. V.

Sahinidis, D. Agarwal, C. Tong, S. E. Zitney, A. Sarkar, X. Sun, S. Sundaresan, E. Ryan, D. Engel, and C. Dale, Annual Review of Chemical and Biomolecular Engineering, Vol 5 5, 301 (2014).

[5] A. B. Rao and E. S. Rubin, Environmental Science \& Technology 36, 4467 (2002).

[6] R. Siriwardane and C. Robinson, Journal of Environmental Engineering-ASCE 135, 378 (2009).

[7] S. Sjostrom and H. Krutka, Fuel 89, 1298 (2010).

[8] L. Barelli, G. Bidini, and F. Gallorini, Applied Energy 162, 58 (2016).

[9] R. W. Breault and E. D. Huckaby, Applied Energy 112, 224 (2013).

[10] E. M. Ryan, D. DeCroix, R. Breault, W. Xu, E. D. Huckaby, K. Saha, S. Dartevelle, and X. Sun, Powder Technology 242, 117 (2013).

[11] M. Syamlal and T. J. O'Brien, AIChE Journal 49, 2793 (2003).

[12] N. Xie, F. Battaglia, and R. O. Fox, Combustion Theory and Modelling 8, 195 (2004).

[13] S. Gerber, F. Behrendt, and M. Oevermann, Fuel 89, 2903 (2010).

[14] W. L. Oberkampf and T. G. Trucano, Progress in Aerospace Sciences 38, 209 (2002).

[15] E. M. Ryan, C. Montgomery, C. Storlie, and J. Wendelberger, CCSI Validation and Uncertainty Quantification Hierarchy for CFD Models (CCSI Technical Report, 2012).

[16] C. Lai, Z. Xu, W. Pan, X. Sun, C. Storlie, P. Marcy, J.-F. Dietiker, T. Li, and J. Spenik, Powder Technology 288, 388 (2016).

[17] R. Sanz, G. Calleja, A. Arencibia, and E. S. Sanz-Perez, Applied Surface Science 256, 5323 (2010).

[18] P. D. Vaidya and E. Y. Kenig, Chemical Engineering \& Technology 30, 1467 (2007).

[19] D. G. Schaeffer, Journal of Differential Equations 66, 19 (1987).

[20] D. Gidaspow, Multiphase Flow and Fluidization: Continuum and Kinetic Theory Descriptions (Academic Press, San Diego, 1994).

[21] S. Benyahia, M. Syamlal, and T. J. O'Brien, Summary of MFIX Equations 2012-1, https://mfix.netl.doe.gov/download/mfix/mfix_current_documentation/MFIXEquations2012-

1.pdf.

[22] M. Syamlal, MFIX Documentation: Numerical Techniques, https://mfix.netl.doe.gov/download/mfix/mfix_legacy_manual/numerics.pdf.

[23] K. Agrawal, P. N. Loezos, M. Syamlal, and S. Sundaresan, Journal of Fluid Mechanics 445, 151 (2001).

[24] A. T. Andrews, P. N. Loezos, and S. Sundaresan, Industrial \& Engineering Chemistry Research 44, 6022 (2005).

[25] Y. Igci, A. T. Andrews, S. Sundaresan, S. Pannala, and T. O'Brien, AIChE Journal 54, 1431 (2008).

[26] Y. Igci, S. Pannala, S. Benyahia, and S. Sundaresan, Industrial \& Engineering Chemistry Research 51, 2094 (2012). 
[27] Y. Igci and S. Sundaresan, AIChE Journal 57, 2691 (2011).

[28] Y. Igci and S. Sundaresan, Industrial \& Engineering Chemistry Research 50, 13190 (2011).

[29] C. C. Milioli, F. E. Milioli, W. Holloway, K. Agrawal, and S. Sundaresan, AIChE Journal 59, 3265 (2013).

[30] A. Sarkar, X. Sun, and S. Sundaresan, Chemical Engineering Science 104, 399 (2013).

[31] J.-F. Parmentier, O. Simonin, and O. Delsart, AIChE Journal 58, 1084 (2012).

[32] Wen and Yu, AIChE Journal 12, 610 (1966).

[33] C.-Y. Wen and Y. Yu, Chemical Engineering Progress Symposium Series 62, 100 (1966).

[34] Y. Igci, Closures for coarse-grid simulation of fluidized gas-particle flows (Ph.D. Dissertation, Princeton University, 2011).

[35] W. A. Lane, E. M. Ryan, A. Sarkar, and S. Sundaresan, in ASME 2014 International Mechanical Engineering Congress and Exposition (American Society of Mechanical Engineers, 2014), pp. V08AT10A060.

[36] A. Sarkar, X. Sun, and S. Sundaresan, Chemical Engineering Science 114, 144 (2014). 


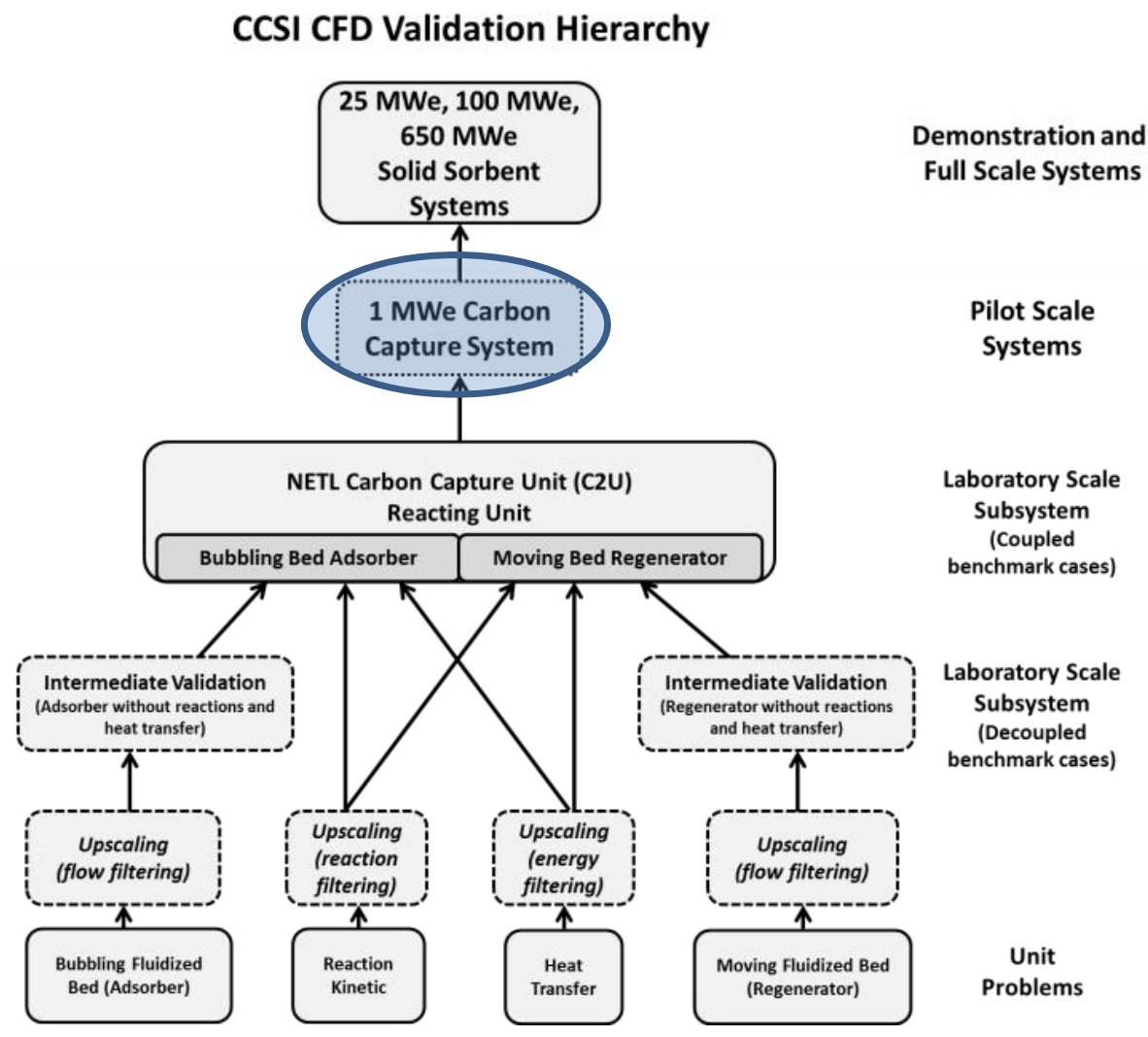

Figure 1. CCSI hierarchical calibration and validation framework. 
Two-stage (trayed) adorber column conceptual design
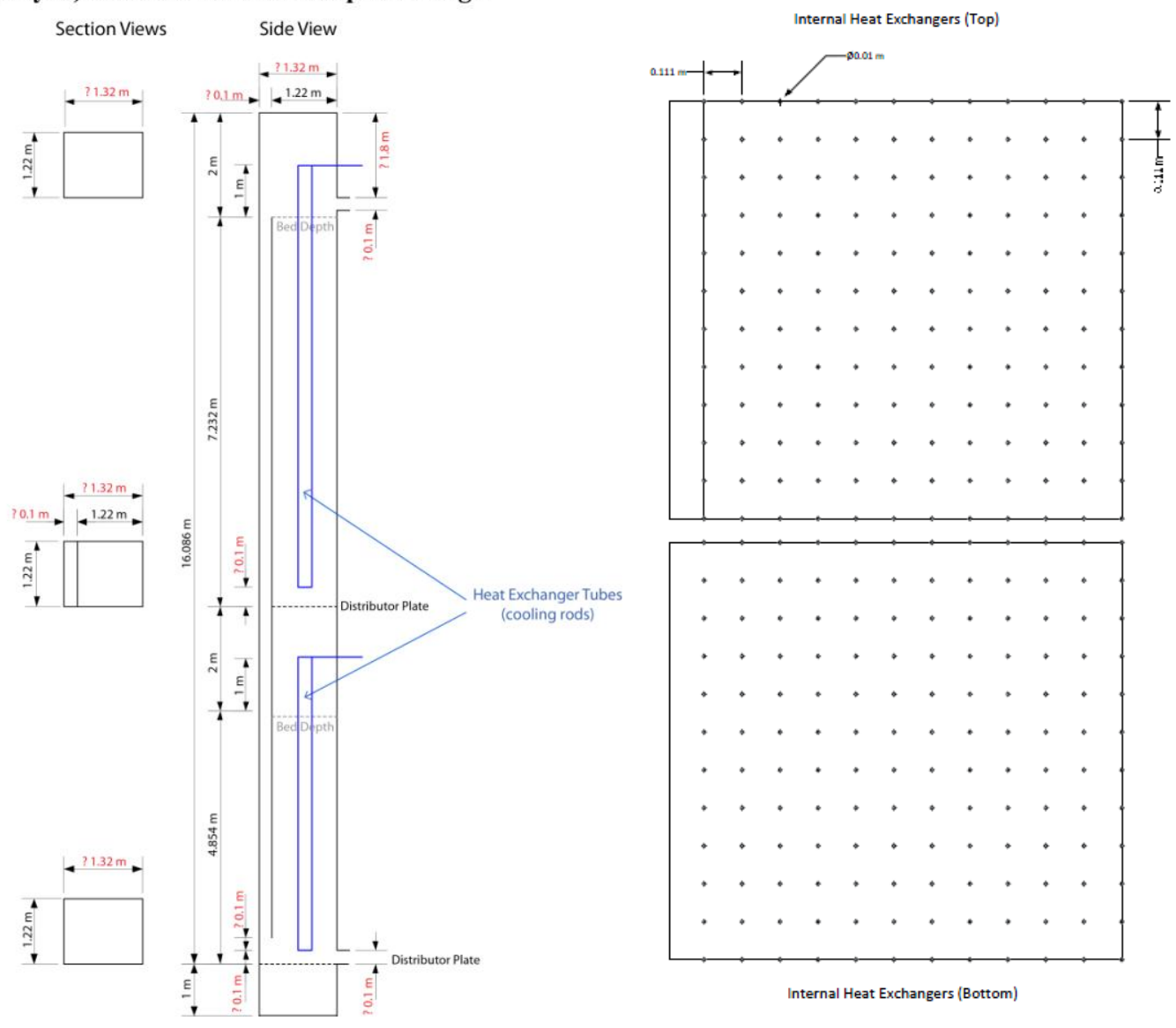

Figure 2. Schematic of a two-stage trayed adsorber column design for a 1-MW pilot-scale system (left) and internal heat exchangers or cooling tubes (right). 


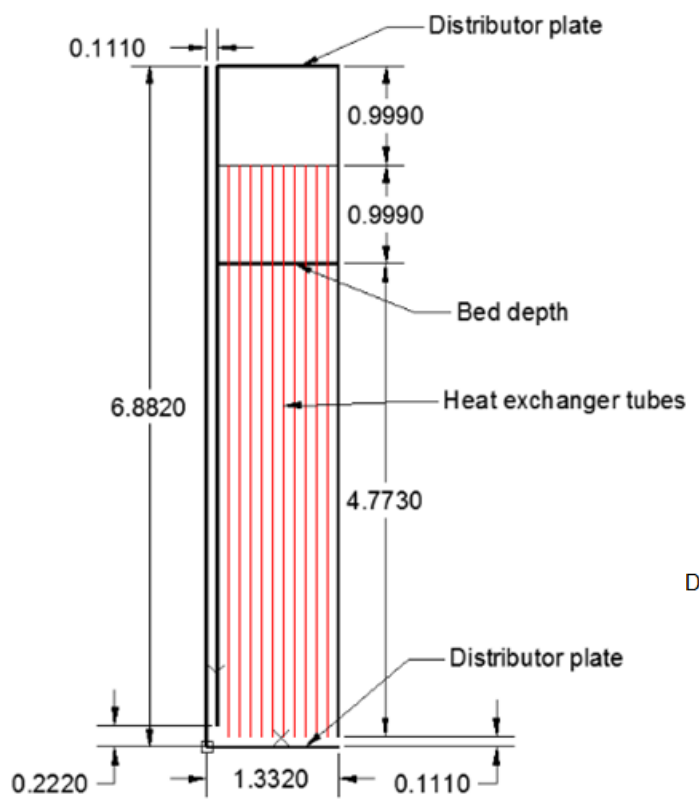

(a)

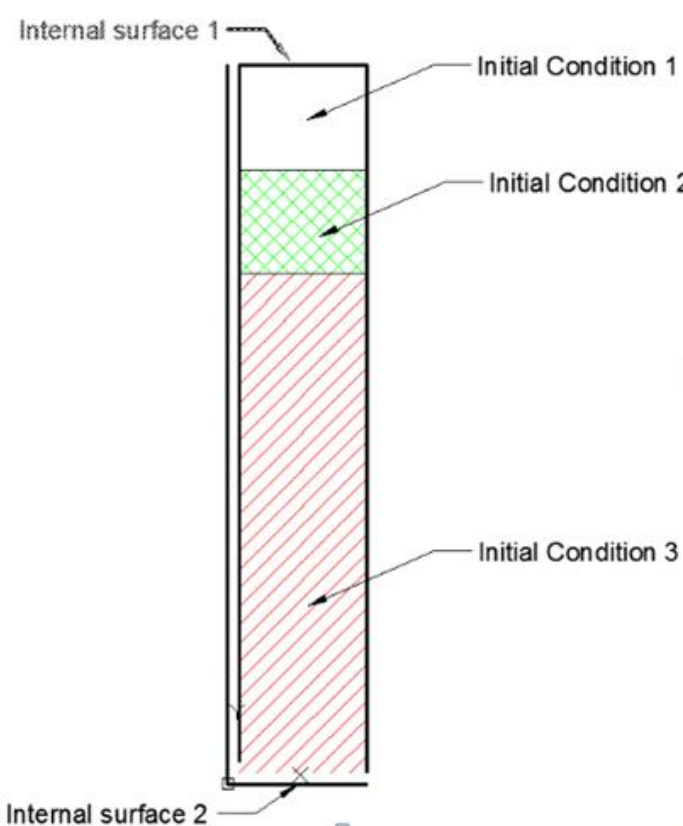

(c)

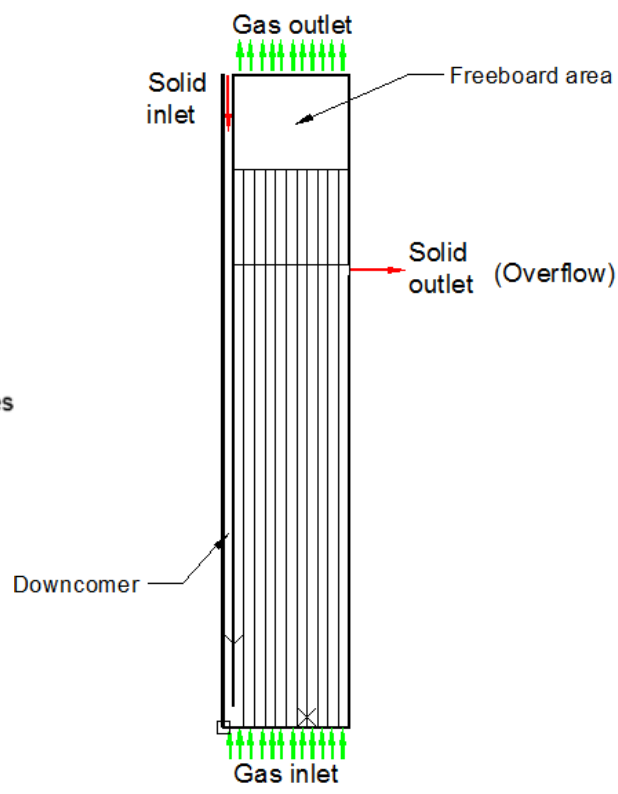

(b)

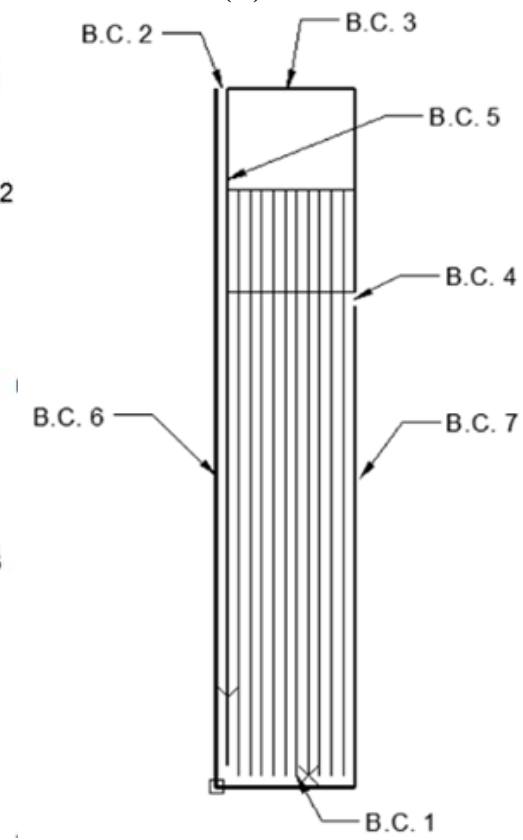

(d)

Figure 3. (a) CFD model geometry and dimension in the unit of meter ( $4.773 \mathrm{~m}$ is the process design of the bed depth), (b) solid and gas inlet and outlet, (c) initial conditions, and (d) boundary conditions used in MFIX. 


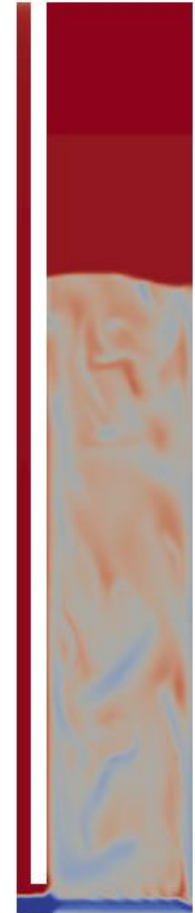

a)

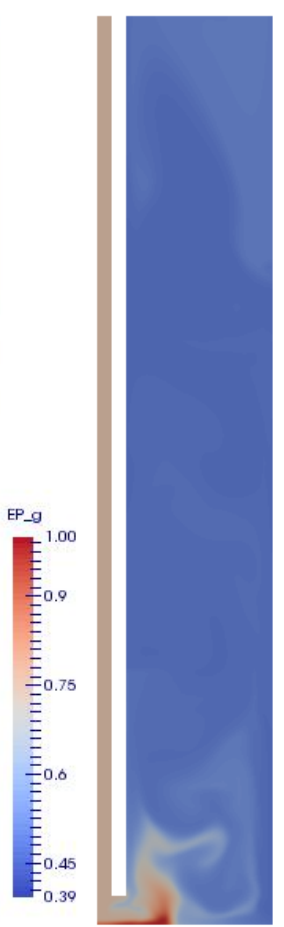

b)

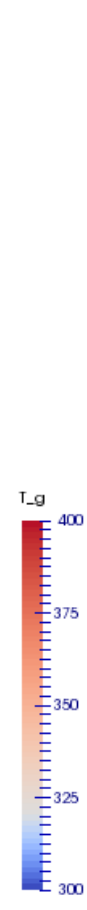

c)

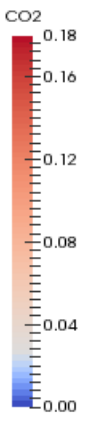

Figure 4. Snapshots of spatial distributions of a) voidage, b) gas phase temperature (K), and 


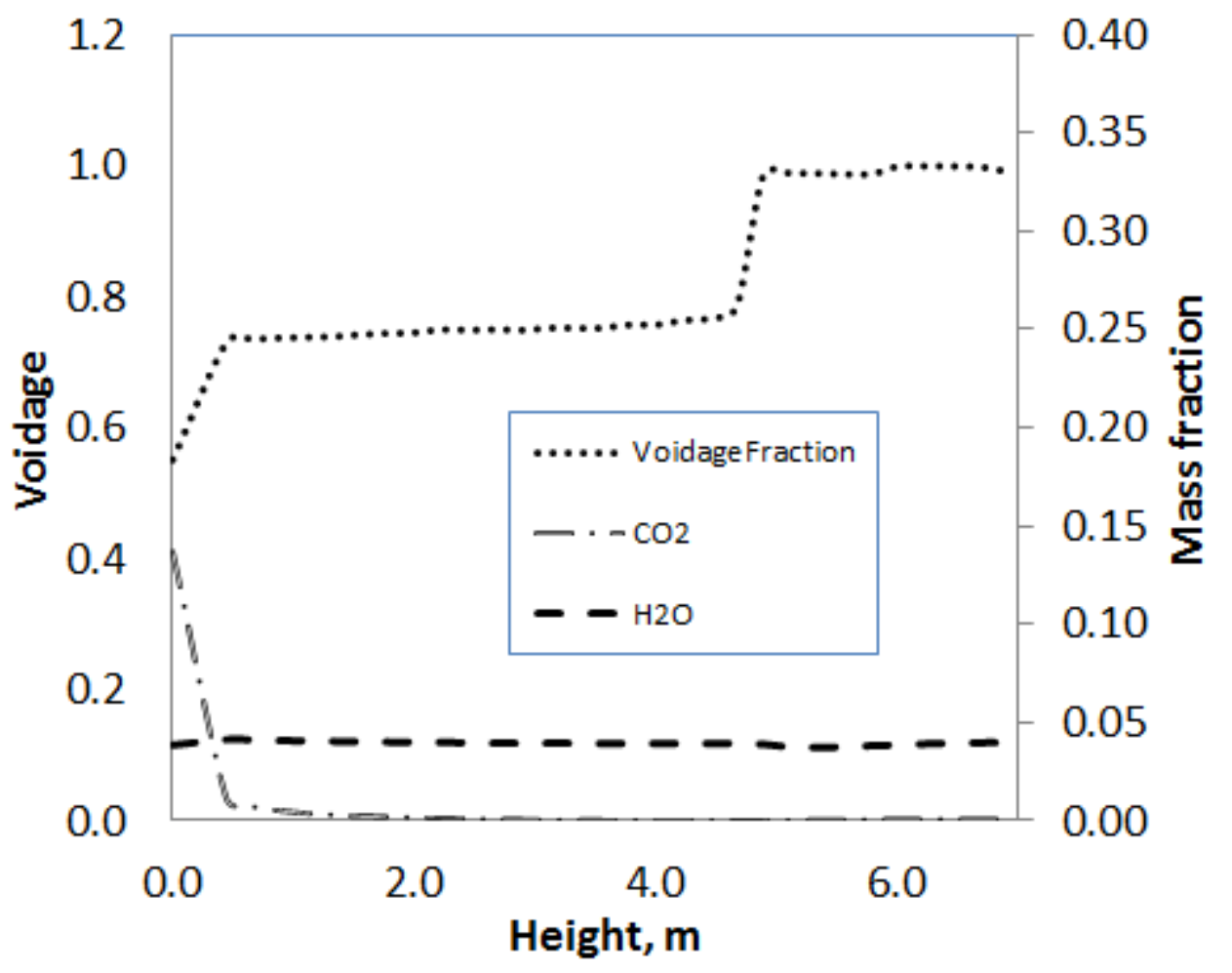

Figure 5. Distribution of cross-sectional averaged gas voidage, $\mathrm{CO}_{2}$, and $\mathrm{H}_{2} \mathrm{O}$ mass fraction along the adsorber height for a flow rate of $0.60 \mathrm{~kg} / \mathrm{s}$. 

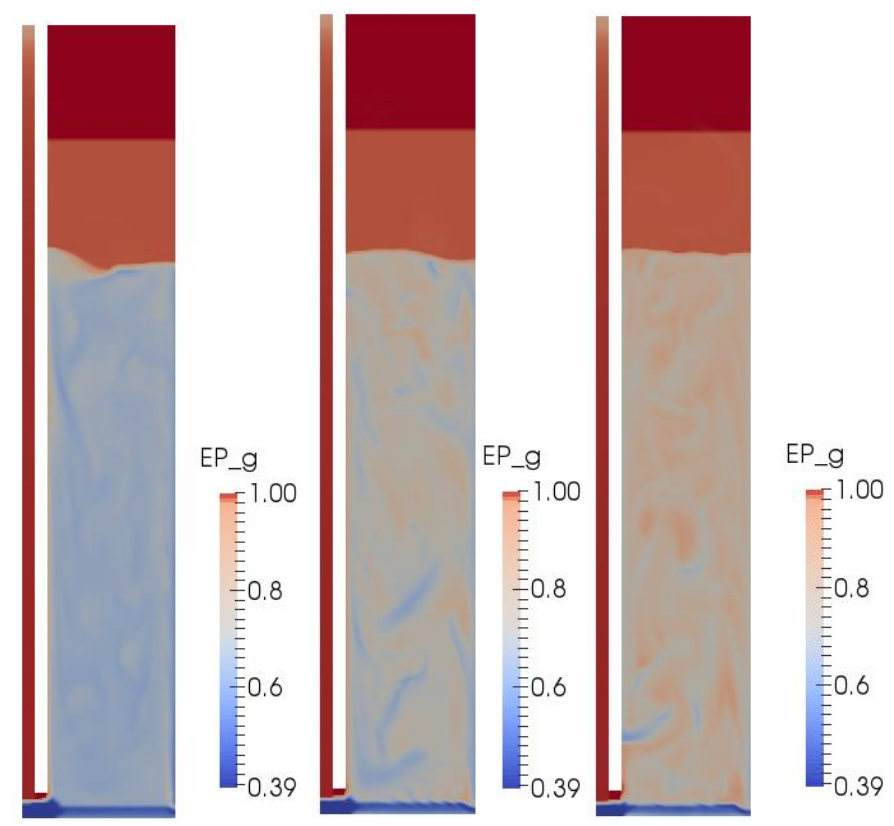

Figure 6. Effect of gas flow rate on the spatial distributions of voidage. From left to right, the voidage distribution is depicted for gas flow rates of $0.36,0.6$, and $0.84 \mathrm{~kg} / \mathrm{s}$. 


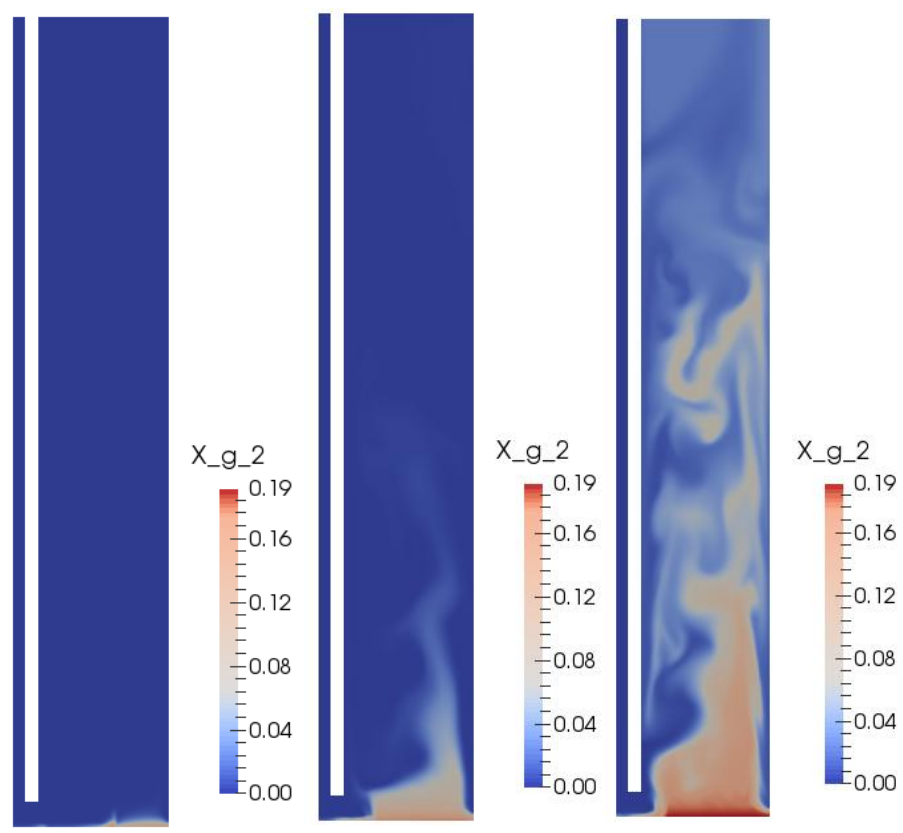

Figure 7. Effect of gas flow rate on the spatial distribution of $\mathrm{CO}_{2}$ mass fraction. From left to right, the distribution of $\mathrm{CO}_{2}$ mass fraction is shown for gas flow rates of $0.36,0.60$, and 0.84 $\mathrm{kg} / \mathrm{s}$. 


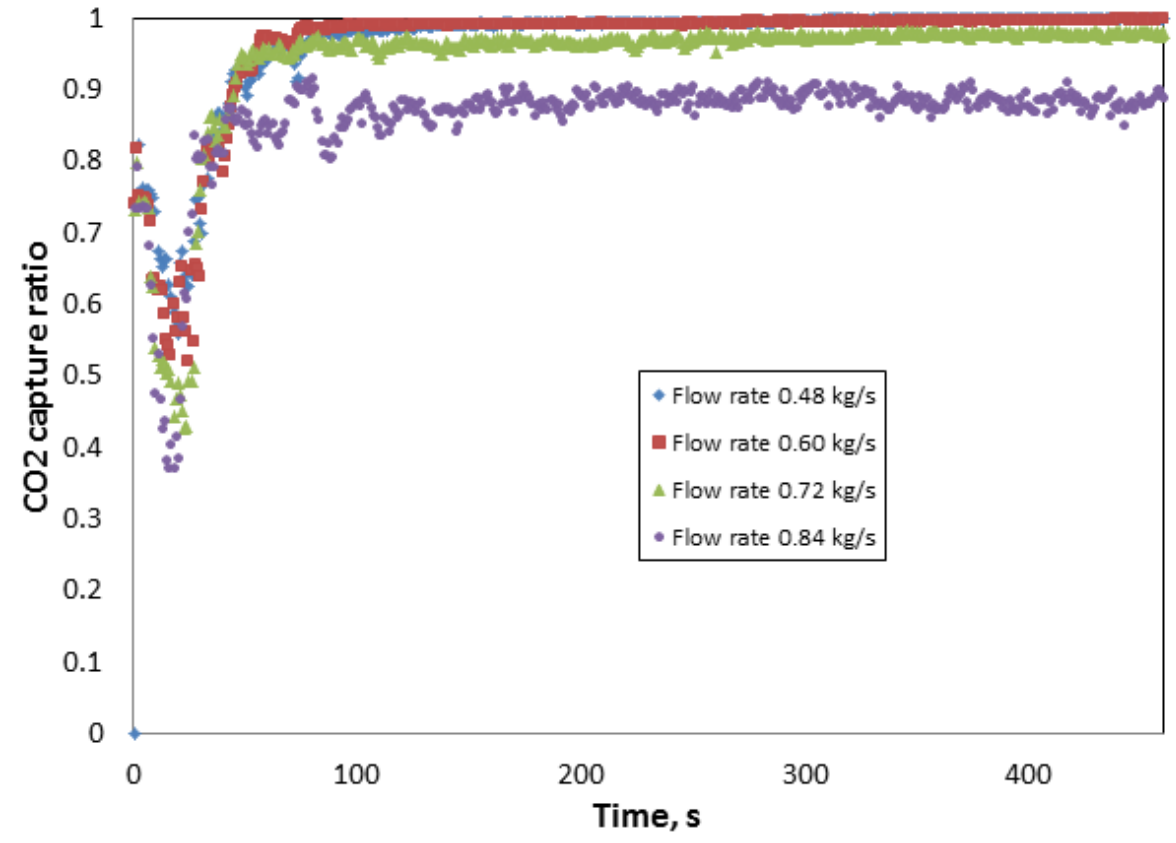

Figure 8. Transient $\mathrm{CO}_{2}$ absorption fraction varying with simulation tome for three different gas flow rates. 


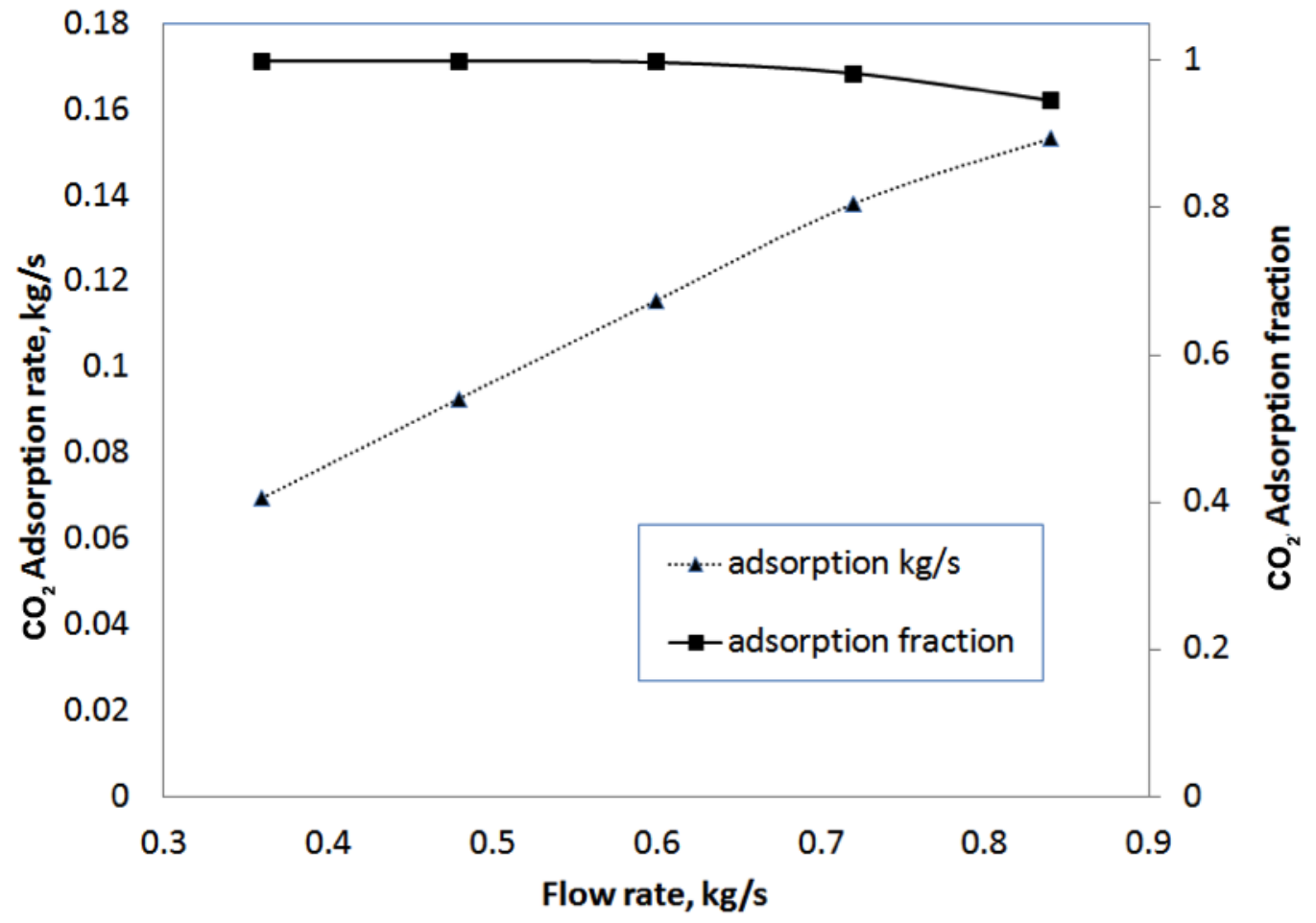

Figure 9. $\mathrm{CO}_{2}$ adsorption rates and adsorption fractions versus flow rates. 
Fraction of $\mathrm{CO}_{2}$ Adsorbed at $0.72 \mathrm{~kg} / \mathrm{s}$

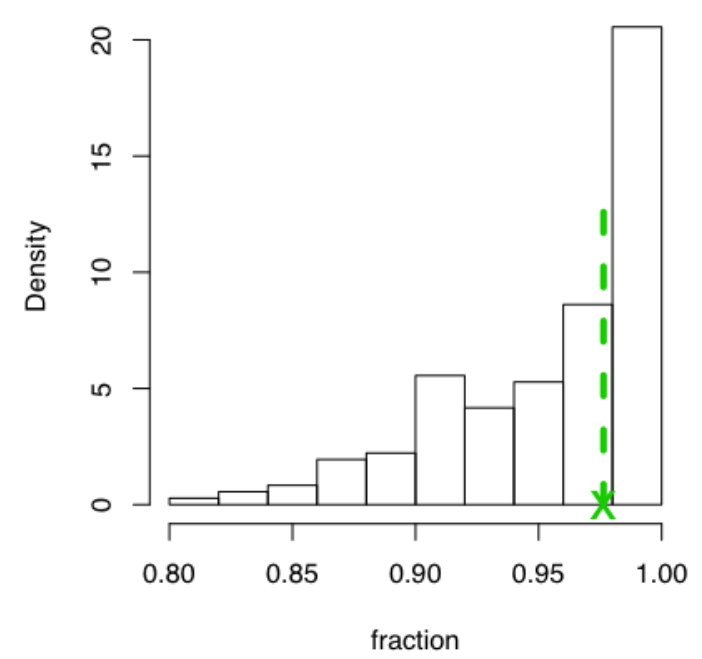

Bed Heights at $0.72 \mathrm{~kg} / \mathrm{s}$

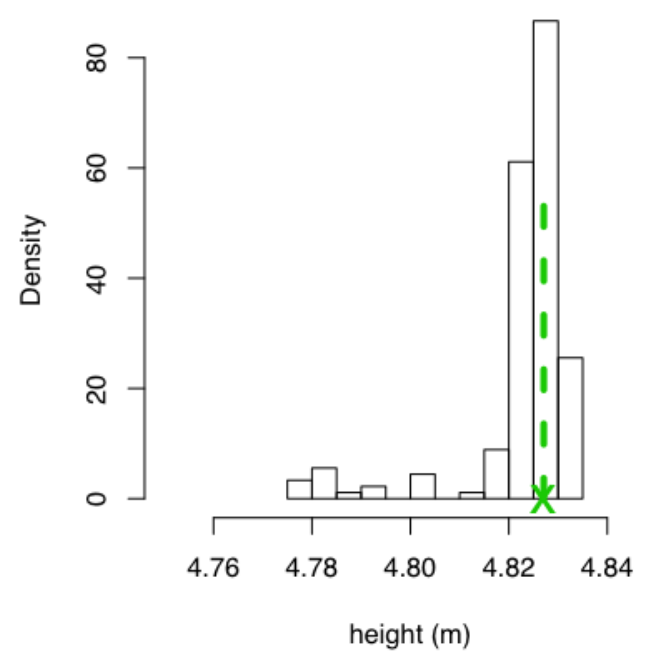

Figure 10. Histograms showing the variability of capture fraction and bed height stemming from the variability in uncertain simulation inputs (231 successful runs at the flow rate of $0.72 \mathrm{~kg} / \mathrm{s}$ ). The green " $\mathrm{x}$ " indicates the nominal input values. 


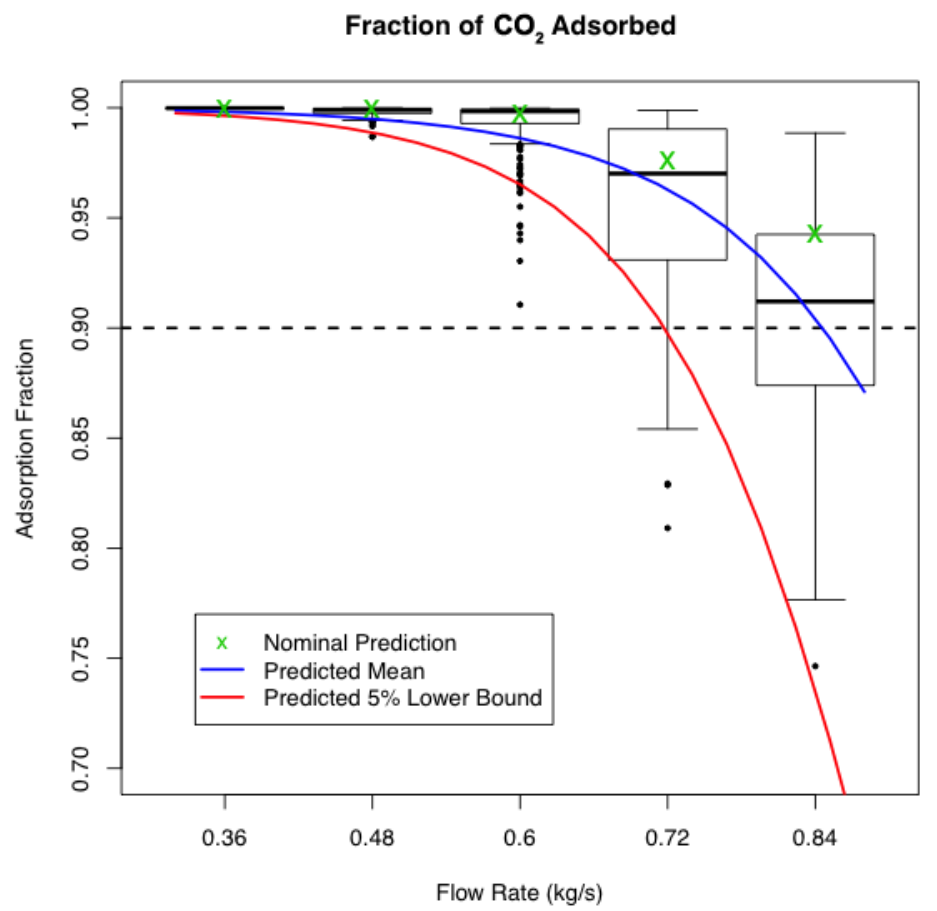

Figure 11. Side-by-side boxplots showing the uncertainty distributions of capture fraction for the ensemble of simulations at five different flow rates. 


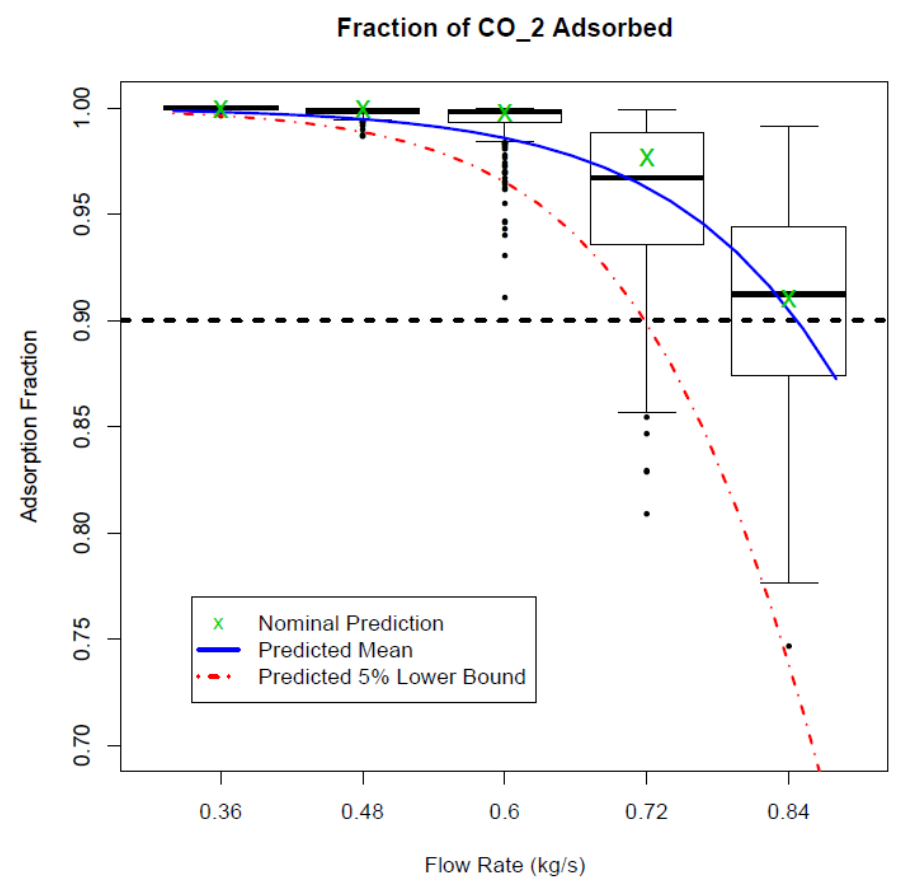

Side-by-side boxplots showing the uncertainty distributions of capture fraction for the ensemble of simulations at five different flow rates. 